\title{
Assessment of Bacteriological Contamination of the Zambian Paper Currency in Circulation in Selected Areas of Lusaka City, Zambia
}

\author{
Adriace Chauwa ${ }^{1}$, Geoffrey Kwenda ${ }^{1}$, Sydney Malama ${ }^{2 *}$, Patrick Kaonga ${ }^{3}$, Henry Mwelwa \\ Chimana $^{1}$ \\ ${ }^{1}$ University of Zambia, School of Health Sciences, Department of Biomedical Sciences, Zambia \\ ${ }^{2}$ University of Zambia, School of Natural Sciences, Department of Biological Sciences, Zambia \\ ${ }^{3}$ University of Zambia, School of Public Health, Department of Epidemiology and Biostatistics, Zambia \\ *Corresponding Author: Sydney Malama, University of Zambia, School of Natural Sciences, Department \\ of Biological Sciences, Zambia
}

\begin{abstract}
Money has been implicated in many studies as a vector of various pathogens, bacteria inclusive. It is one of the few fomites that is widely circulated in the population and thus has great potential of harbouring potentially infectious pathogens.

This study aimed at screening the Zambian paper currency, the Kwacha, for bacterial contamination and to test the isolates for antimicrobial susceptibility patterns.

This was a laboratory-based study that involved the collection of 120 paper money samples via aseptic technique and was conducted from 2018 to 2019. The study population included sub regions of the city, Lusaka. They included, Kabwata, Kalingalinga and Chilenje townships as well as Lusaka City Market Lusaka, Zambia. The collected samples were then transported to the Microbiology laboratory for swabbing, inoculation and further analysis. Inoculation was done on blood agar and Mackonkey agar, followed by identification using biochemical tests and antimicrobial susceptibility testing were performed on Mueller Hinton agar using standard antimicrobial discs.

Eight (8) species of bacteria were isolated from the Zambian currency notes including Bacillus species, Corynebacterium species, Listeria monocytogenes, Coagulase-negative Staphylococcal species, Staphylococcus aureus, Proteus species, E. coli, Enterococcus species. Ciprofloxacin, Tetracycline and Amikacin were the most efficacious drugs, while most resistance was noted to Penicillin G, Cefoxitin and Cotrimoxazole. The most contaminated currency note was ZMK2.00 and the ZMK 1.00 note was the less contaminated.

Conclusion: This study isolated eight pathogenic species of bacteria from the Zambian Currency notes and they showed resistance to some commonly used drugs. These results indicate that currency notes have the potential to transfer potentially pathogenic organism and may be also be a suitable platform for evolution and spreading of antimicrobial resistance. There is need for public education on good hygiene practices When handling paper currency in Zambia.
\end{abstract}

Key words: Zambia, Kwacha, Bacteria, Currency, Contamination

\section{INTRODUCTION}

Paper money first came into use around $1000 \mathrm{AD}$ in China and has since been used as a medium of economic exchange and is one of the most circulated materials in the modern world (Alemu 2014)... (Edward, et al, 2011). Despite being impregnated with bacteriostatic disinfectants, pathogens have been isolated from currency notes such as viruses, bacteria, and spirochetes for instance. Money is, therefore, a fomite in circulation which has an overlooked vehicle of potential pathogens (Alemu 2014).

Paper money has a large surface area and being a medium of exchange of goods and services, is passed from one individual to another hence has the potential of transferring pathogenic organisms (Akintola, et al, 2011). During money exchanges, there may be instrumental in the transfer of microorganisms if it gets contaminated by microorganisms from the gastro-intestinal tract or the respiratory tract when being handled (Gedik, et al, 2013). 
It is common practice that some individuals may not wash or disinfect their hands after coughing, sneezing, use of public toilets and other unhygienic practices. If money is handled by such individuals, the probability of contamination is very high. This confirms the findings from previous reports that there is a high prevalence of microorganisms on notes and coins which increases the chance of transferring pathogens from person to person (Moosavy, et al., 2013). As far as literature was searched we did not come across a study conducted in Zambia on currency contamination and therefore we set out to assess bacteriological contamination of the Zambian paper currency in circulation.

\section{MATERIALS AND MeTHODS}

This was a cross-sectional study and money was randomly collected from every day use from; Lusaka City Market, Kabwata and Chilenje market as well as mini-bus conductors within Lusaka city. A total of 120 samples in denominations of 2, 5, 10,20,50 and $100 \mathrm{kwach}$ notes were obtained. These places are densely populated and are business-oriented areas therefore money is in frequent and constant circulation. The paper money was from individuals after they were requested to drop the notes in a sterile bag and then labelled appropriately. Upon collection via aseptic technique samples were then transported to the Microbiology laboratory at Ridgeway Campus School of Health Sciences in Lusaka for swabbing, inoculation and further analysis.

\subsection{Isolation of Bacteria from the Paper Currency}

Briefly, a sterile cotton swab moistened with sterile physiological saline was used to swab both sides of each note. To isolate bacteria, the swabs were used to inoculate on Blood agar, MacConkey agar plates by streaking. The plates were then incubated aerobically at $35-37^{\circ} \mathrm{C}$ for $24-48$ hours to allow organisms to grow. Pure cultures were obtained by streaking a small portion of cells from an isolated colony on the corresponding medium and incubating plates over night at $35^{\circ} \mathrm{C}-37^{\circ} \mathrm{C}$.

\subsection{Identification of Bacterial isolates}

Colonial morphology as well as haemolytic reactions was observed. Pure cultures were Gram-stained and subsequently tested using standard biochemical tests such as catalase, coagulase, oxidase, sugar fermentation, indole, citrate utilization, urease production and motility test.

\subsection{Determination of Drug-Susceptibility of Bacterial isolates}

Bacteria were tested for susceptibility to antibiotics by the Kirby-Bauer disc diffusion technique following guidelines of the National Committee for Clinical and Laboratory Standards Institute. Fourteen different antibiotic discs representing used were; Amoxicillin (AML, $30 \mu \mathrm{g}$ ), Ampicilin (AMP, $10 \mu \mathrm{g}$ ), Cefotaxime (CTX, $30 \mu \mathrm{g}$ ), Cotrimoxazole (SXT, $25 \mu \mathrm{g}$ ), Erythromycin (E, $15 \mu \mathrm{g}$ ), Gentamicin (CN, $10 \mu \mathrm{g})$, Oxacillin (OX, $1 \mu \mathrm{g})$, Penicillin G (P, $10 \mu \mathrm{g})$, Tetracycline (TE, $30 \mu \mathrm{g})$ and Vancomycin (VA, $30 \mu \mathrm{g})$. Susceptibility assay was performed on Mueller-Hinton agar plates. Briefly a suspension of the test organism was prepared to match the $0.5 \% \mathrm{McF}$ arland standard. Plates were then swabbed with the cell suspension and allowed to dry for 10 minutes. Different antimicrobial discs were placed on the inoculated plates ensuring adequate contact of disc and medium. Plates were incubated at $37^{\circ} \mathrm{C}$ for 24 hours, examined and the diameter of the zone of inhibition measured using a graduated ruler. The diameters were then compared with recommended standards, which conform to those of the Clinical Laboratory Standard Institute (CSLI).

\section{RESULTS}

\subsection{Isolation of Bacteria from the Zambian Paper Currency}

A total of 120 money samples were collected from 4 different sites; 30 from each site. Overall, the results indicated that there was $99.3 \%$ bacterial contamination of the currency notes. The total number of bacterial isolates was 124 which belonged to 8 different genera. Out of all the 124 isolates, 39 (31.5\%) were Corynebacterium species, 28 (22.6\%) Bacillus species, 18 (14.5\%) Listeria monocytogenes, $10(8.1 \%)$ coagulase negative Staphylococcus (CoNS), 8 (6.6\%) Enterococcus species, 4 (3.2\%) E.coli, 8 (6.6\%) Staphylococcus aureus, 1(0.8\%) Proteus species and 8 (6.6\%) were group B, $\mathrm{C}, \mathrm{F}$ Streptococcal species as reflected in figure 4.1 below. 


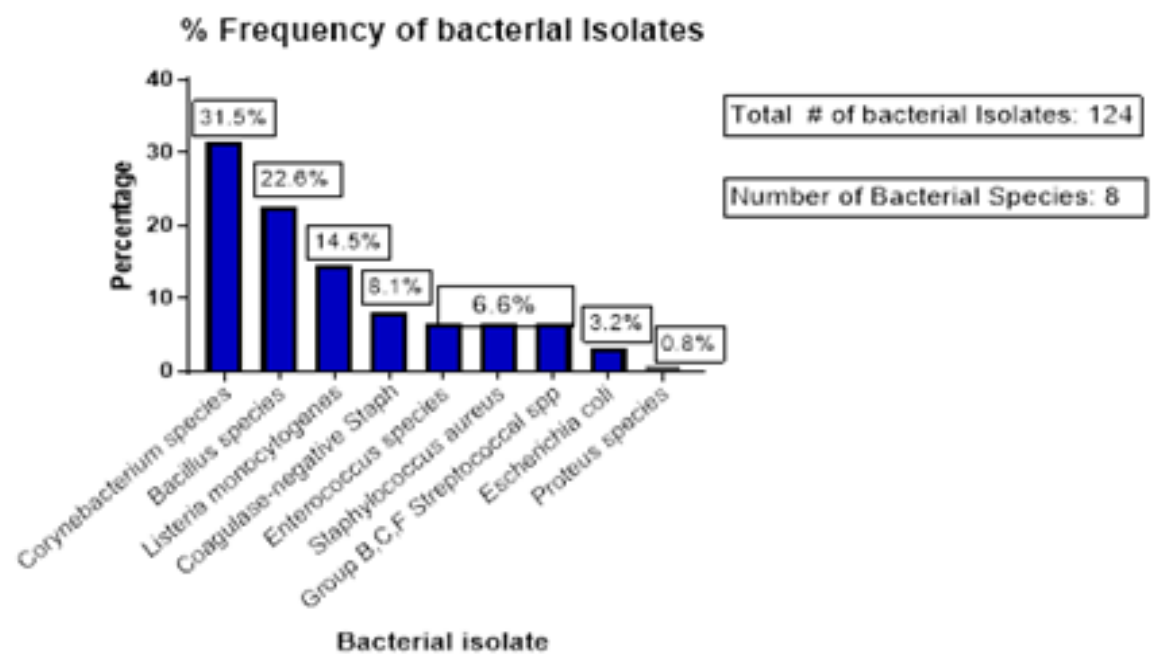

Figure1. Overall Frequency of bacterial isolates

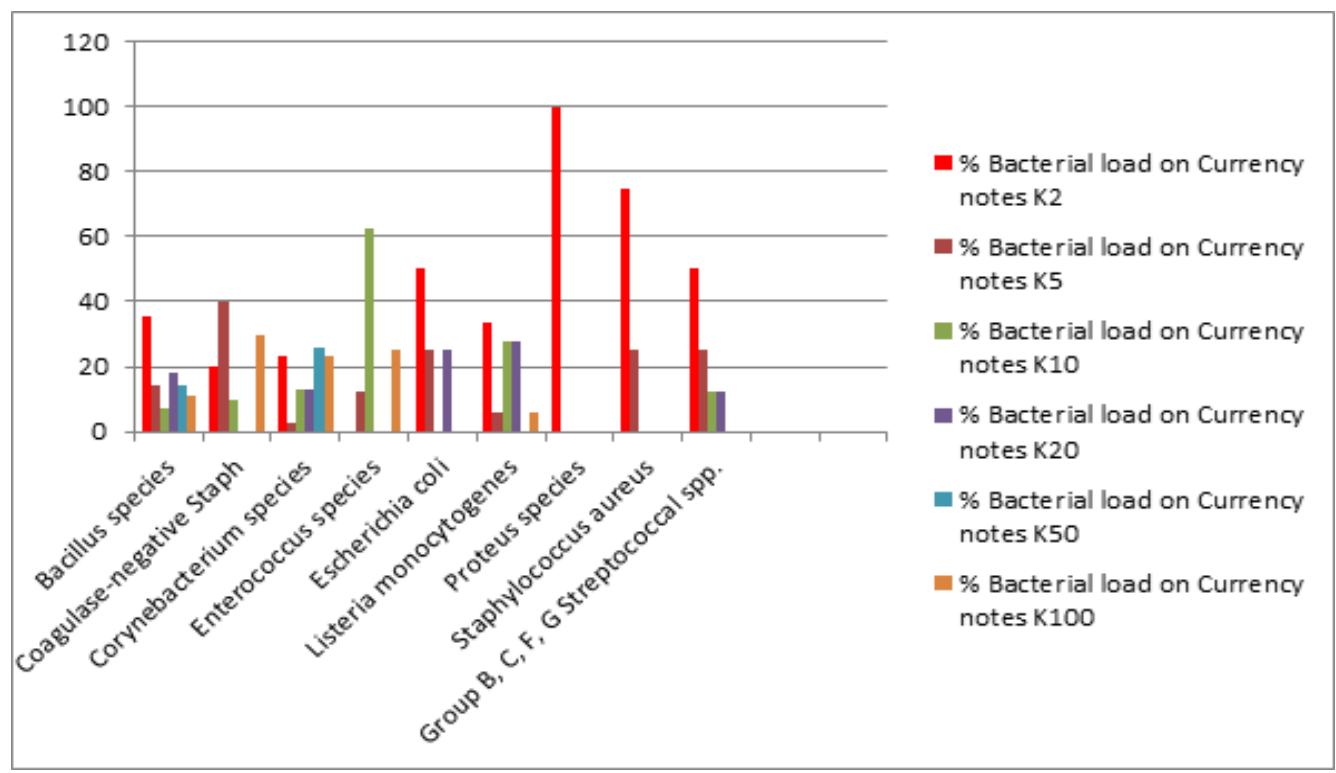

Figure2. Distribution of bacterial contamination among currency notes; type and percentage of bacteria isolated from each currency denomination

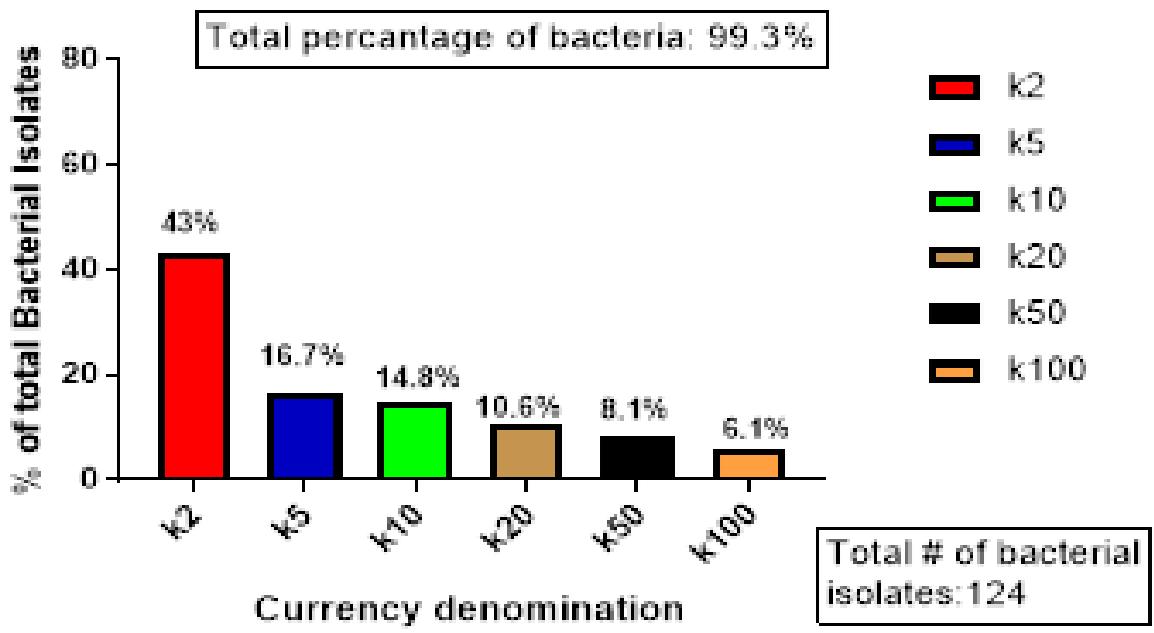

Figure3. Determination of the most contaminated currency note; this figure shows the percentage bacterial load on each currency denomination from the highest to the least contaminated note. 
Assessment of Bacteriological Contamination of the Zambian Paper Currency in Circulation in Selected Areas of Lusaka City, Zambia

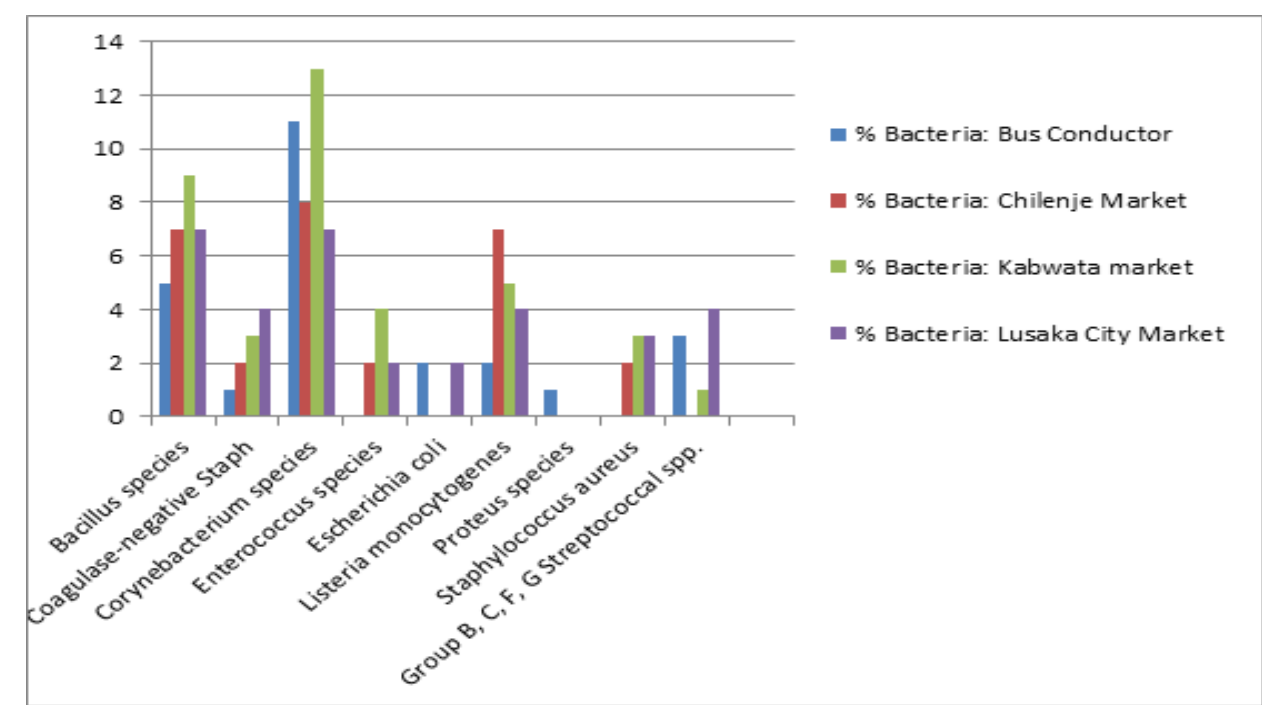

Figure4. Distribution of bacteria among sampling sites; this shows the distribution of bacterial isolates across all 4 sampling sites.

Table1. Antimicrobial Susceptibility Patterns of Bacterial Isolates

\begin{tabular}{|c|c|c|c|c|c|c|c|c|c|c|}
\hline \multirow[t]{2}{*}{$\begin{array}{l}\text { Antimicrobia } \\
\text { l Agent }\end{array}$} & \multicolumn{2}{|c|}{ Bacillus spp. } & \multicolumn{2}{|c|}{ CONS } & \multicolumn{2}{|c|}{$\begin{array}{c}\text { Corynebacterium } \\
\text { spp. }\end{array}$} & \multicolumn{2}{|c|}{ S.aureus } & \multicolumn{2}{|c|}{$\begin{array}{l}\text { Enterococcus } \\
\text { species }\end{array}$} \\
\hline & $\% \mathrm{~S}$ & $\% \mathbf{R}$ & $\% \mathrm{~S}$ & $\% \mathbf{R}$ & $\% \mathrm{~S}$ & $\% R$ & $\% \mathrm{~S}$ & $\% R$ & $\% S$ & $\% R$ \\
\hline Amikacin & 75 & 25 & 90 & 10 & 32 & 68 & 100 & 0 & 60 & 40 \\
\hline Tetracyclin & 26 & 74 & 70 & 30 & 36 & 64 & 72 & 28 & 40 & 60 \\
\hline Cotrimoxazole & 25 & 75 & 0 & 44 & 20 & 80 & 38 & 68 & 70 & 30 \\
\hline Penicillin $\mathrm{G}$ & 3 & 97 & 0 & 100 & 30 & 70 & 25 & 75 & 0 & 100 \\
\hline Cefoxitin & 4 & 96 & 20 & 70 & 10 & 90 & 38 & 68 & 29 & 71 \\
\hline Ciprofloxacin & 86 & 14 & 100 & 0 & 87 & 13 & 75 & 25 & 62 & 38 \\
\hline
\end{tabular}

$\%$ : Percentage Sensitive: \%R: percentage Resistant

Table2. Antimicrobial Susceptibility Patterns of Bacterial Isolates

\begin{tabular}{|l|c|c|c|c|}
\hline \multirow{2}{*}{ Antimicrobial Agent } & Group B, $\boldsymbol{C}, \boldsymbol{F}$, Streptococcal spp. & \multicolumn{2}{c|}{ Listeria monocytogenes } \\
\cline { 2 - 4 } & $\boldsymbol{\%} \mathbf{S}$ & $\mathbf{\%} \mathbf{R}$ & $\mathbf{\%} \mathbf{~}$ & $\mathbf{\text { R }}$ \\
\hline Amikacin & $55 \%$ & $45 \%$ & 75 & 25 \\
\hline Tetracycline & 100 & 0 & 66 & 34 \\
\hline Cotrimoxazole & 60 & 40 & 40 & 60 \\
\hline Penicillin G & 0 & 100 & 6 & 94 \\
\hline Cefoxitin & 0 & 100 & 12 & 88 \\
\hline Ciprofloxacin & 100 & 0 & 94 & 6 \\
\hline
\end{tabular}

$\%$ : Percentage Sensitive: \%R: percentage Resistant

Table3. Antimicrobial Susceptibility patterns of bacterial isolates

\begin{tabular}{|l|c|c|c|c|}
\hline \multirow{2}{*}{ Antimicrobial Agent } & \multicolumn{2}{c|}{ Proteus spp. } & \multicolumn{2}{c|}{ E.coli } \\
\cline { 2 - 5 } & $\mathbf{\%}$ & $\mathbf{\%} \mathbf{R}$ & $\mathbf{\%}$ & \% \\
\hline Tetracycline & 100 & 0 & 100 & 60 \\
\hline Ampicilin & 0 & 100 & 0 & 40 \\
\hline Gentamycin & 100 & 0 & 100 & 100 \\
\hline Amoxyclav & 100 & 0 & 100 & 25 \\
\hline Erythromycin & 100 & 0 & 100 & 0 \\
\hline
\end{tabular}

\%: Percentage Sensitive: \%R: percentage Resistant

\section{DISCUSSION}

The study findings suggest that currency notes represent a significant vehicle for human pathogens. A total of 124 bacterial isolates belonging to 8 different species were obtained and all currency notes were 
found to be contaminated with bacteria. These results are in agreement with the a study in the USA which showed that $100 \%$ of cotton dollar bills were contaminated with bacterial (Benítez, et al., 2016). Findings from another study in Poland also showed that $98 \%$ of the Polish notes were contaminated with bacteria (Kalita, et al., 2013).

Similar results were obtained in a study conducted in Ghana which yielded had a total of eight bacterial species from Cedi, the Ghanaian notes while Ethiopian paper currency had five bacterial species only (Girma, et al., 2014 and Alemu 2014). Studies in Nigeria and South Africa had more isolates with 13 and 12 bacterial species respectively (Sa and Adeyiyi 2011; Potgieter and Mkasi, 2007). The correlation in the results obtained from this study in relation to other studies are attributable to factors such as sampling frame, sample size as well as the habitat and ecology of the isolated bacteria. Other factors may be survival rate of pathogens on the currency notes as well as methods used to isolate them.

In the current study however, the most prevalent isolates were Corynebacterium species accounting for $31.5 \%$ of the total number of bacterial isolates followed by bacillus species with $22.6 \%$. The presence of Corynebacterium species and Bacillus species on the currency notes indicate environmental contamination. These bacteria are generally common environmental organisms thus may contaminate surfaces and fomites such as currency notes in this case. Similar findings were obtained in Ghana and Ethiopia though the highest frequency in both studies was that of Bacillus species followed by Corynebacterium (Girma, et al., 2014; Alemu, 2014). In a similar study conducted in Ghana, Corynebacteria and most Bacillus species were also isolated and their significance is that they do not typically cause infection in normal healthy individuals but have been implicated in the immunocompromised individuals; such as HIV/AIDS patients as well as hospitalised patients (Girma, et al., 2014). Isolation of Listeria monocytogenes in this study also correlated with a study in Iran which also had the same bacteria (Moosavy, et al., 2013). The primary reservoir for L.monocytogenes is soil and water and is frequently associated with dairy products, vegetable and other undercooked meat. Victims that fall prey to this pathogen are the immunocompromised patients, foetuses as well as neonates. It usually affects the brain and meninges with a $20 \%$ death rate in some cases.

Other bacteria isolated in this study were Enterococcus species, Staphylococcus aureus and Group B, $C$ and $F$ Streptococcal species. These results are consistent with those found in other studies in Poland where Enterococcus species, had a bacterial load of $9 \%$ whilst in Tanzania a $7.4 \%$ prevalence of Staphylococcus aureus was found and in Ethiopia 9.3\% of Streptococcal species were isolated (Kalita, et al., 2013; Neel, 2013; Alemu, 2014). Streptococcal species isolated in this study may be linked to a wide range of infections mostly of the skin and mucous membranes whilst other virulent strains are associated with brain infections such as Streptococcus agalactiae (citation). Enterococcus species isolated also pause a significant threat to in a category of individuals. These bacteria do not typically cause disease in immunocompetent individuals but may be aetiological in the incidence of certain enteric opportunistic infections in the immunocompromised or hospital acquired infections (Girma, et al., 2014) what is the implication of this findings.

E. coli and Proteus species were the only enterobacteriaceae isolated in this study and accounted. Other studies also isolated these two organisms for example, in Nigeria, E.coli was at 3.8\% whilst a higher prevalence of 7.9\% was found to be Proteus species in South Africa (SA \& Adeyiyi 2011; Potgieter and Mkasi, 2007).

The most contaminated currency note of all the denominations was the ZMK2 note which harboured the majority of the total bacteria isolated then ZMK5 followed by the ZMK10 and the ZMK20 notes. The ZMK50 and ZMK100 notes had the least bacterial contamination. It was also observed from this study that the ZMK2 note is the only denomination which harboured all 8 species of bacteria and is also the only note which had E. coli and Proteus species. This phenomenon can be attributed to lower denomination notes are more widely circulated than their higher counter parts and so tend to go through probably the most unhygienic conditions as they are in transit from one person to another more frequently. This confers a high probability of harbouring highly pathogenic organisms such as the invasive skin infections and toxin-mediated shock caused by S.aureus and the diarrhoeal diseases associated with E.coli.

The presence of staphylococcal species is usually indicative of contamination from the skin, mouth, or nose whilst some strains, including coagulase-negative, can cause a number of diseases ranging from 
opportunistic infections in skin and other tissues to pneumonia and Toxic Shock Syndrome (TSS). E. coli on currency notes indicates faecal contamination which may be associated with diarrhoeal diseases especially the pathogenic strain O157:H7 (Jiang and Doyle, 1999; Ehwarieme, 2012). Faecal contamination of the currency notes reflects the unhygienic handling it undergoes as it circulates from one individual to another under varied environmental conditions. On the other hand, the isolated Proteus species may be implicated in urinary tract infections. The similar results obtained in other studies reflect to a certain extent, the myriad of unhygienic conditions under which money is handled (Jiang and Doyle, 1999). Paper money has the ability to be manipulated and stored in various ways and different environments. This could also be why the distribution of bacteria on them is so wide and characterised bacteria from different ecological settings ( Ehwarieme, 2012).

From the results of this study, it can be inferred that the lower the currency denomination, the higher the contamination and the higher the denomination, the lower the contamination. This trend is consistent with the findings from other studies which indicated that lower denomination notes were showed the highest contamination and vice-versa (Lamichhane et al., 2009; Neel, 2013 and Augusto, et al., 2015).

From the distribution results of bacterial across the 4 sampling sites, the highest number of isolates was Corynebacterium species from Kabwata market then conductors, then followed by Chilenje market and Lusaka City market. This random distribution can be attributed to a no single factor since no other possibly confounding variables were taken into account in this research as the activities that take place in these areas are similar.

Antimicrobial susceptibility patterns to the 9 selected antimicrobial agents used in this study showed various patterns. A high level of resistance to penicillin $\mathrm{G}$ and cefoxitin was observed in most of the isolates. Most Bacillus spp. were susceptible to amikacin and ciprofloxacin but resistant to penicillin, tetracycline, cotrimoxazole and cefoxitin. S. aureus and L.monocytogenes isolates were susceptible to amikacin, tetracycline and ciprofloxacin while resistant to cotrimoxazole, penicillin $\mathrm{G}$ and cefoxitin. Most Corynebacterium spp. were susceptible to ciprofloxacin only and resistant to amikacin, tetracycline penicillin, cotrimoxazole and cefoxitin implying that treatment options for an infection caused by these species would be narrow in reference to this list of antibiotics.

Enterococcus spp. and Group B, C, F Streptococcal spp. were susceptible to amikacin, tetracycline and ciprofloxacin but showed resistance to penicillin G, cefoxitin and cotrimoxazole. For the enterobacteriaceae that were isolated, Proteus spp. responded well to most antibiotics i.e., Tetracycline, Gentamicin, AmoxyClav, Ciprofloxacin and Erythromycin and showed resistance to only one drug, Ampicillin. On the other hand, E. coli was susceptible to ampicillin, erythromycin, amoxyClav and ciprofloxacin, whilst resistant to tetracycline and gentamicin.

A similar pattern of antimicrobial resistance was seen in Nigeria where all the bacteria isolates showed $100 \%$ resistance to amoxicillin, $87.5 \%$ resistance to tetracycline, chloramphenicol and streptomycin, whilst 50\% showed resistance to cotrimoxazole and gentamycin (SA and Adeyiyi et al., 2011). ciprofloxacin, amikacin and tetracycline proved to be the most efficacious drugs in this report and this correlates with the results obtained in Nigeria where $100 \%$ bacterial isolates were susceptible to Ciprofloxacin (SA and Adeyiyi, 2011).

The Antimicrobial resistance recorded in this report is similar to many globally experienced problems and is also a major cause of morbidity and mortality in addition to the difficulty in treatment of infections. The burden of antimicrobial resistance is mostly apparent in populations where cheaper and easily available drug choices are limited due to the phasing out of resistant drugs coupled with the lack of an alternative option as experienced in other countries (SA and Adeyiyi, 2011 and Neel, 2012).

As a preventive and control measure, it is important for the global community to take a multidisciplinary approach to control and limit the use and availability of antibiotics in order to reduce the burden of antimicrobial resistance.

\section{CONCLUSION}

Eight species of bacteria were isolated from the Zambian Currency notes including Bacillus species, Corynebacterium species, Listeria monocytogenes, Coagulase-negative Staphylococcal species, Staphylococcus aureus, Proteus species, E.coli, Enterococcus species and Group B, C, F streptococcal species. Antimicrobial susceptibility patterns were determined and Ciprofloxacin, Tetracycline and 
Amikacin as the most efficacious drugs, while resistance was noted in Penicillin G, Cefoxitin and Cotrimoxazole. These results indicate that currency notes have the potential to transfer potentially pathogenic organism and may be also be a suitable platform for evolution and spreading of antimicrobial resistance. There is need for public education on good hygiene practices with money especially when it is coupled with the simultaneous handling of food for example, washing of hands before and after handling of money and food. It would also be imperative for the central bank and other financial institutions to incorporate minting as well as disinfection services on any currency notes coming into their facility and possibly replacing highly soiled notes.

\section{ACKNOWLEDGEMENT}

The authors wish to thank, Mr Tembo, Mr Mandanda, Mrs Bwalya and Mr Polepole, for the technical support and resource acquisition. We would also like to thank the participants who provided money samples for the accomplishment of this task.

\section{CONFLICT OF INTEREST}

The authors declare no conflict of interest

\section{FUNDING SOURCES}

Self-sponsorship

\section{REFERENCES}

[1] Akoachere, J.T.K., Gaelle, N., Henry, M.D and Nkuo-Akenji, T.K. (2014). Public health implications of contamination of Franc CFA ( XAF) circulating in Buea ( Cameroon ) with drug resistant pathogens. Biomed Central Reseearch Notes. available at http://www.biomedcentral.com/1756-0500/7/16. Accessed: 5-10-2015.

[2] Alemu A., (2014). Microbial Contamination of Currency Notes and Coins in Circulation: A Potential Public Health Hazard., 2(3): 46-53.

[3] Benítez, N.A., Gómez, A.F. and Meza, J.M. (2016). Bacteriological Analysis of Circulating Money Bills at The University of The Pacific, Paraguay. FELSOCEM, 2013: 31-33.

[4] Bhat, N., Bhat, S., Asawa, K. and A.A. (2010). An Assessment of Oral Health Risk Associated with Handling of Currency Notes. International Journal of Dental Clinics, 2(3): 14-16.

[5] Bishal, D., Lamichhane, J., Satish, A., Prson, G. and Rajani, M. (2009). Risk of Handling Paper Currency in Circulation Chances of Potential Bacterial Transmittance. Nepal Journal of Science and Microbiology, 10:161-166.

[6] Da Fonseca, T.A.P., Pessôa, R. and Sanabani, S.S. (2015). Molecular Analysis of Bacterial Microbiota on Brazilian Currency Note Surfaces. International Journal of Environmental Research and Public Health, 12: 13276-13288.

[7] Ehywarieme, D.A. (2012). R-Plasmids Amongst E Coli O157:H7 Isolated from Nigerian Currency Notes. International Journal of Tropical Medicine and Public Health, 1:17-22

[8] Gedik, H., Voss, T.A. and V.A. (2013) Money and transmission of bacteria Money and transmission of bacteria. Antimicrobial Resistance and Infection Control, 2(1), p.1.Girma, A., Katema, T. and B. k., 2014. Microbial load and safety of paper currencies from some food vendors in Jimma Town, Southwest Ethiopia. BMC Research Notes, 7(843): 1-8.

[9] Jalali S., Kohil, S., Latka, C., Bhatia, S., Vellarikal, Karuthedath., Sivasubbu, S., Scaria, V. and R.S. (2015). Screening Currency Notes for Microbial Pathogens and Antibiotic Resistance Genes Using a Shotgun Metagenomic Approach. PLoS ONE, 10(6): 1-15.

[10] Jiang X, Doyle MP (1999) Fate of Escherichia coli O157:H7 and Salmonella enteritidis on currency. J Food Protect, 62:805-807.

[11] Kalita, M., Szysz, M.P and Szewczuk, A.T. (2013) Isolation of Cultivable Microorganisms from Polish Notes and Coins. Polish Journal of Microbiology, 62(3): 281-286.

[12] Kalita, M., Palusinska-Szysz M., Turska-Szewczuk, A., Wdowiak-Wrobel, S. and U.-S., (2013). Isolation of Cultivable Microorganisms from Polish Notes and Coins. Polish Journal of Microbiology, 62(3): 281-286.

[13]Lopez, G. U., Gerba, C. P., Tamimi, A. H., Kitajima, M., Maxwell, S. L., \& Rose, J. B. (2013). Transfer efficiency of bacteria and viruses from porous and nonporous fomites to fingers under different relative humidity conditions. Applied and Environmental Microbiology, 79:5728-5734

[14] Moosavy, M., Shavisi, N., Warriner., K. and Mosta-Favi, E. (2013). Bacterial Contamination of Iranian Paper Currency. Iranian Journal of Public Health, 42(9): 1067-1070. 
[15] Neel, R. (2013) Multidrug Resistance of isolates of Methicillin Resistant Staphylococcus aureus (MRSA) in Paper Currency Notes from Restaurants and Hotels in Lusaka in Zambia. International Journal of Pharmacy and Pharmaceutical Sciences, 5(1): 12-15.

[16] Pope, T.W.C., Ender, P.T., Woelk, W.K., Koroscil, M.A. and Koroscil, T.M.C (2002). Bacterial Contamination of Paper Currency. Southern medical journal, 95(12): 1408-1411.

[17] Potgieter, N. \& Mkasi, T.C (2007). Microbiological analysis of banknotes circulating in the Venda region of Limpopo province, South Africa. South African Journal of Science, 6: 365-366.

[18] Rote, R.B., Deogade, N.G. \& Kawale, M. (2010). Isolation, characterization and antibiotic sensitivity of organism from Indian currency Asiatic Journal of Biotechnology Resources, 3: 255-260.

[19] SA., A. and Adeyiyi, (2011). Prevalence and antimicrobial resistance pattern of microorganisms isolated from Naira notes in Ogbomoso North, Nigeria. Journal of Research in Biology, 1(8): 587-593.

Citation: Sydney Malama, et.al (2020). “Assessment of Bacteriological Contamination of the Zambian Paper Currency in Circulation in Selected Areas of Lusaka City, Zambia". International Journal of Research Studies in Microbiology and Biotechnology (IJRSMB), vol. 6, no. 2, pp. 14-21, 2020. Available: DOI: http://dx.doi.org/ 10.20431/2454-9428.0602004

Copyright: (C) 2020 Authors. This is an open-access article distributed under the terms of the Creative Commons Attribution License, which permits unrestricted use, distribution, and reproduction in any medium, provided the original author and source are credited. 